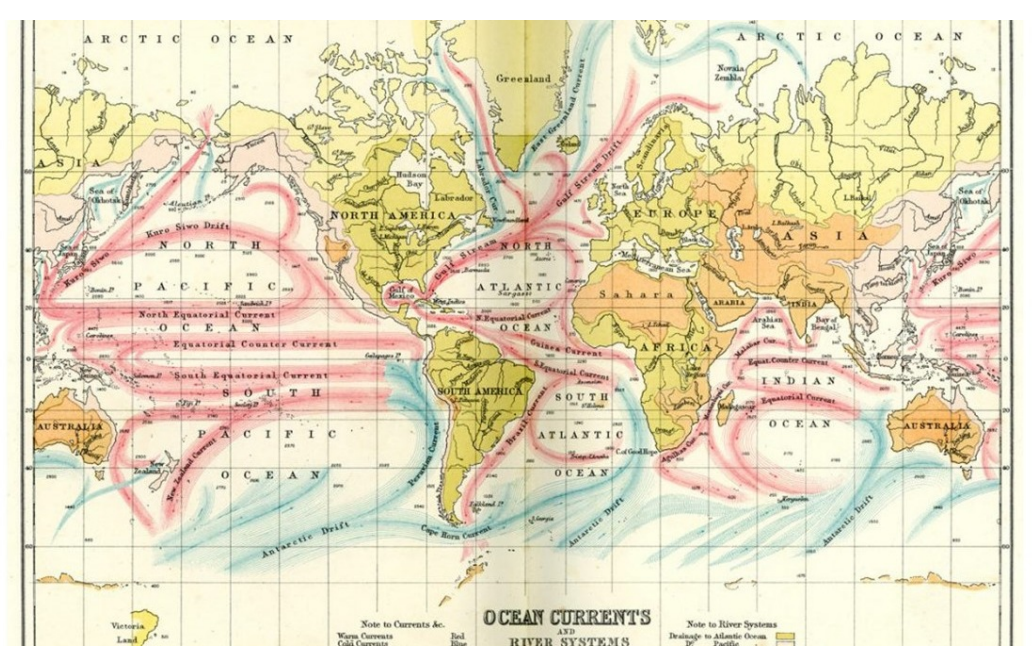

\title{
Gulf Stream gyres may have dictated the outcome of the Covid-19 disease in Western Europe
}

\author{
Carlos Rodriguez 1 \\ 1 Fundación Jiménez Díaz
}

Funding: The author(s) received no specific funding for this work.

Potential competing interests: The author(s) declared that no potential competing interests exist.

\section{Abstract}

When looking at the Covid-19 fatality data on an Atlantic European map, what sticks out is a pattern of often neighboring areas with contrasting mortality rates. In countries like Spain or France, these areas can be grouped into interior (high mortality rates) and coastal (low mortality rates). When we draw the Low Mortality Areas (LMA) as a continuous line throughout the Atlantic European coastline, there is a striking coincidence between the resulting LMA corridor and the coastal area of immediate influence of the Gulf Stream. This coincidence begs the speculation that the two arms of the Gulf Stream may have determined to some exent the outcome of the Covid-19 pandemic in Western Europe.

Unlike other methods of epidemiological accounting (like, for instance, cases per capita or deaths per cases), deaths per capita or deaths per million (dpm), is perhaps the better way of representing the real impact of the pandemic on regions and countries ${ }^{[1]}$. 
provides a graphic way to quickly spot the areas of lower death rates. As shown in figure 1, strikingly, these areas clearly correspond to the open sea Atlantic coast lines of both the Iberian Peninsula and France.

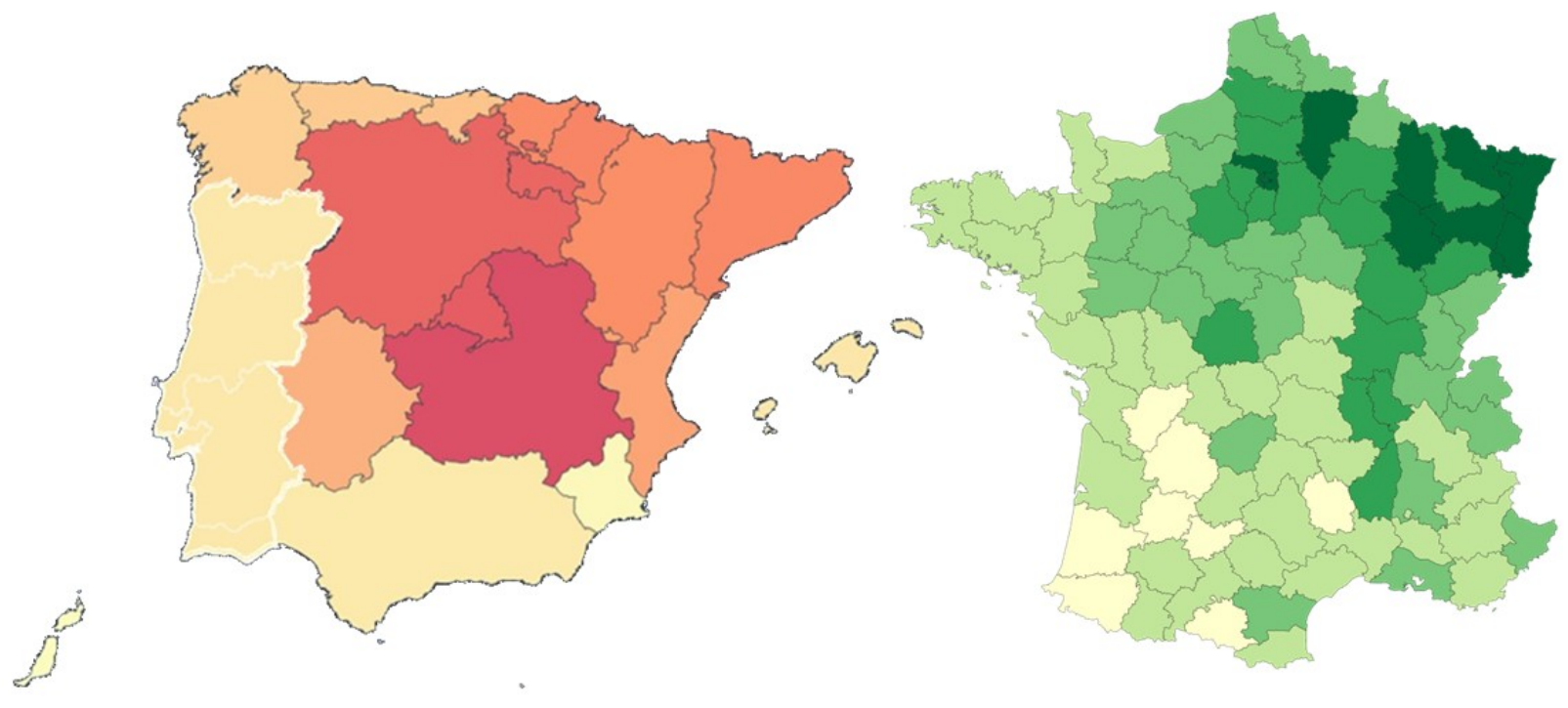

Figure $1 \mathrm{~A}$

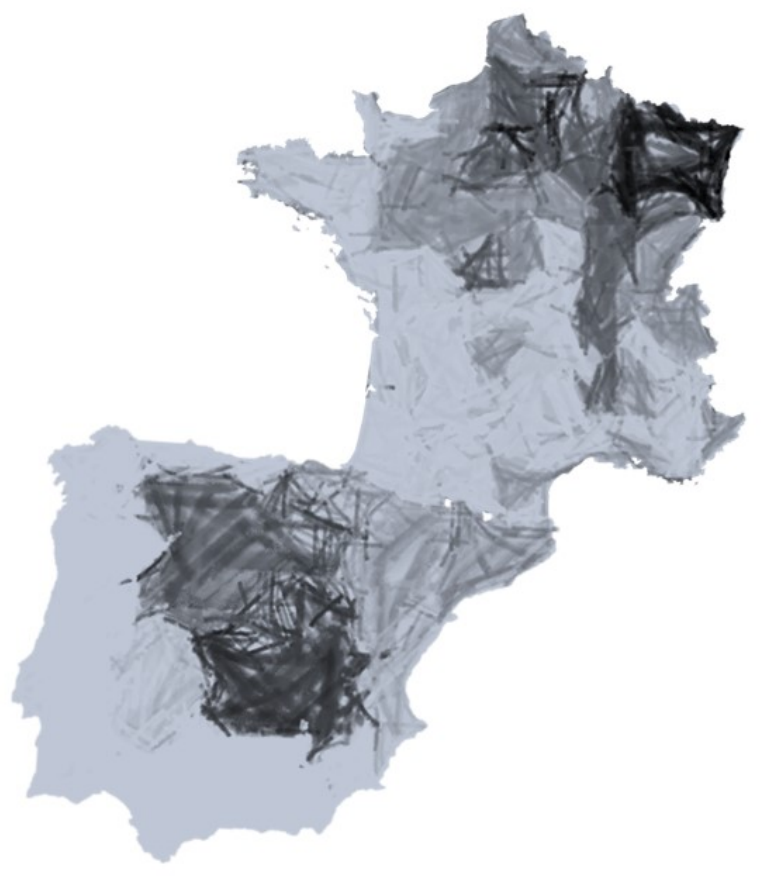

Figure 1B 

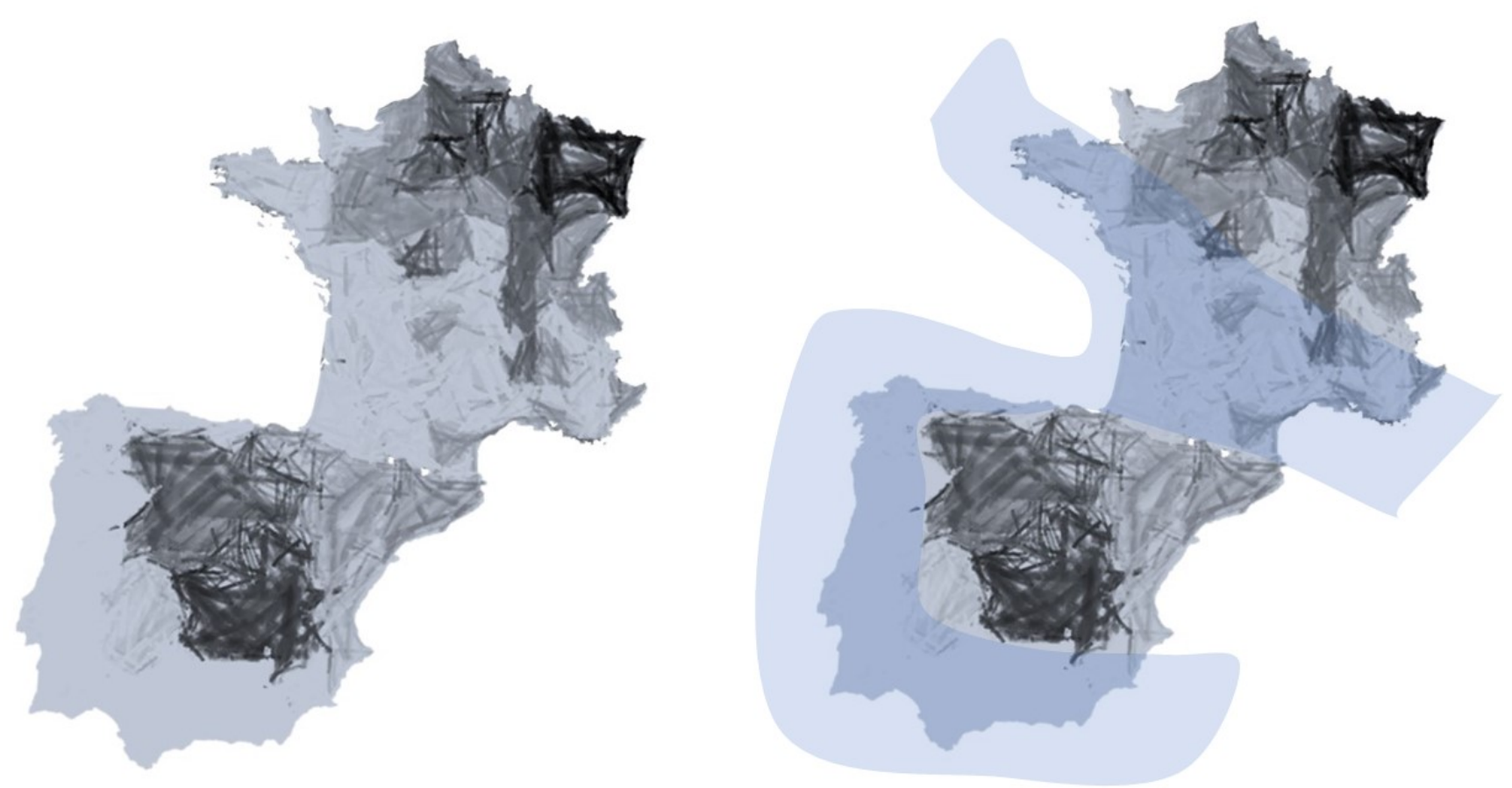

Figure $1 \mathrm{C}$

Figure 1. A. Real cumulative deaths per million (dpm) data are mapped whereby darker hues of red (lberian Peninsula) or green (France) correspond to the highest dpm rates. B. Automatic artistic rendering (powerpoint 2013) of A. C. In light blue, area of lower dpm rates.

If we next follow the open sea coastline of Atlantic Europe, we can easily trace an uninterrupted brim that would start with the Norwegian coastline, would touch Northern Scotland, circumnavigate the Irish coastline towards the Southwest of Ireland (in particular, the Kerry and Cork counties, which have the lowest Covid-19 dpm rates in Ireland), Devon and Cornwall in England (that, again, have consistently recorded the lowest dpm counts in the whole England), continue on an imaginary stream towards France, where the current would hit Bretagne, then follow south to Aquitaine, then will skim along the Spanish North, Portugal and Andalusia, to complete a seamless corridor, a corridor that perfectly delineates the areas of LMA by Covid-19 in Western Atlantic Europe (Figure 2A). What is most striking is that this corridor almost exactly overlaps with the Western European coastline that is directly hit by the circulating ocean currents (or gyres) of the Gulf Stream (figure 2B). 


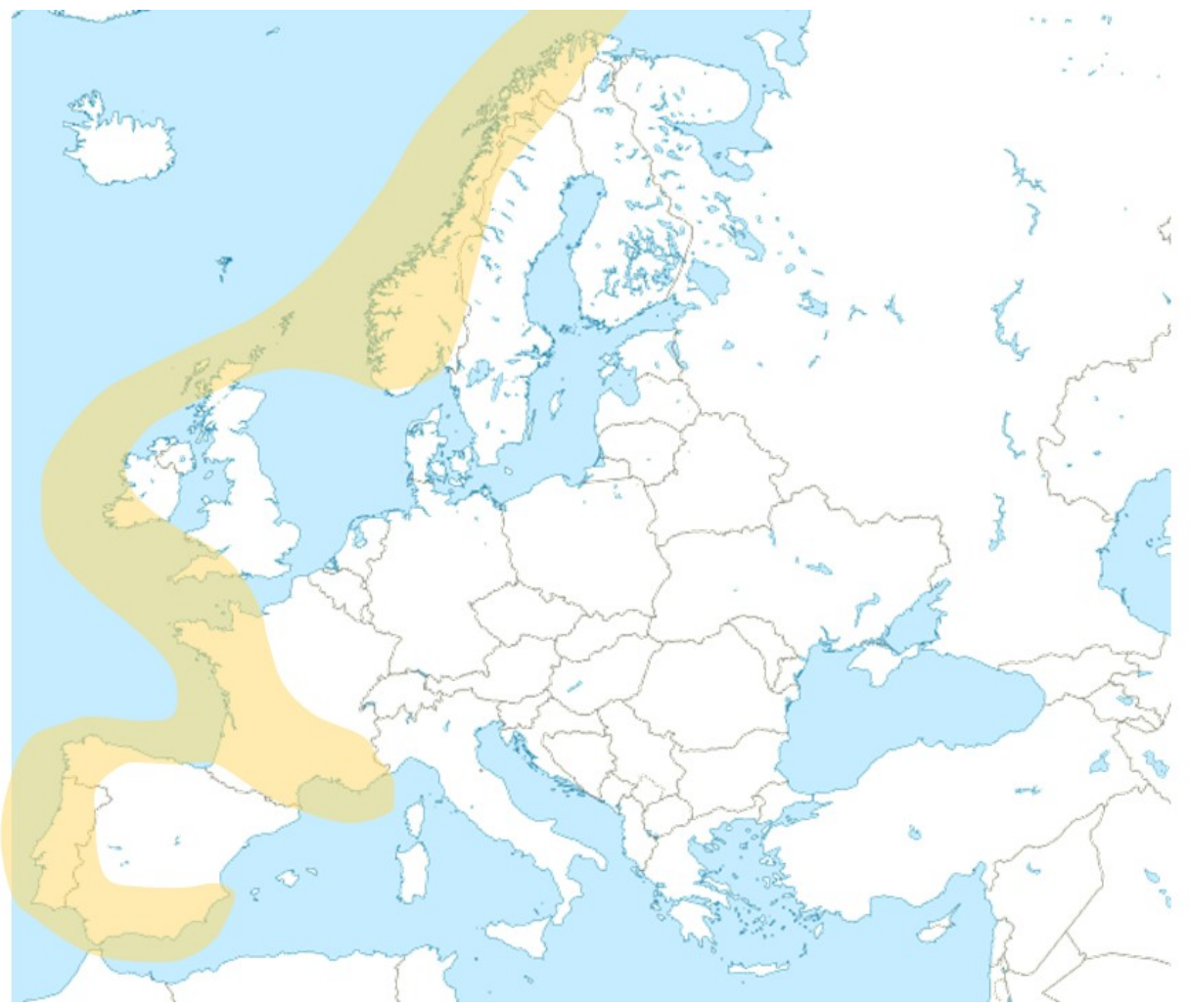

Figure $2 \mathrm{~A}$

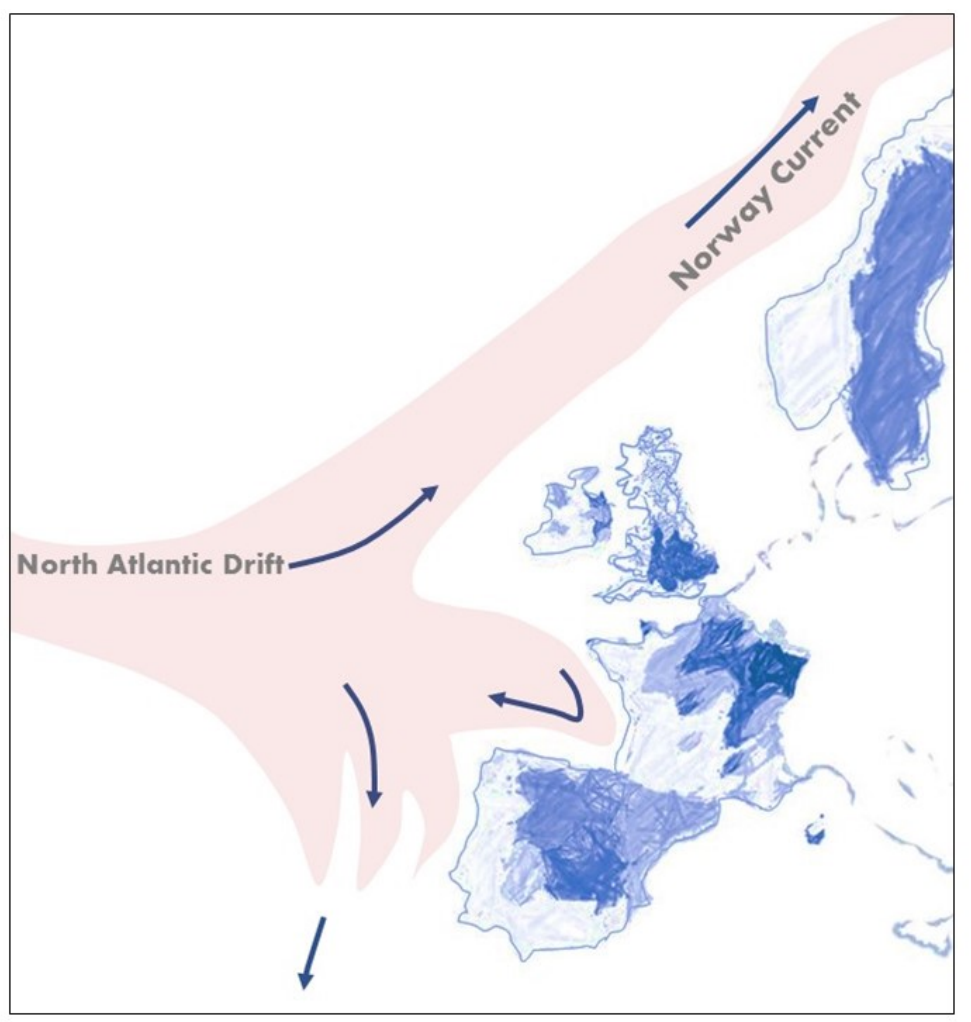

Figure 2B

Figure 2. A. Imaginary fringe following the low Covid-19 dpm trail in Atlantic Europe. B. The Gulf Current (adapted from Encyclopedia Britannica) on a Covid-19 death related artistic map rendering (in darker blue are the areas with higher 
mortality rates).

The Gulf Stream or Thermaline Current is a huge mass of water that travels from the Gulf of Mexico, crossing the Atlantic Ocean eastward and flanking most Atlantic Europe through its two main streams, the North Atlantic Drift and the Norwegian Current northward, and the Canary Stream southward. For a very long time it was believed that the Gulf Stream was the reason for the warmer winters on the west coast of Europe when compared with the west coast of North America at the same latitude. It has now been proven however that geographical/climate factors other than the Stream could account for this effect ${ }^{[2]}$. Whether the observation in the present paper is causal (i.e. the Gulf Stream setting the conditions for a lower Covid-19 death rate) or not, the unequivocal coincidence warrants further observational and/or simulation studies to ascertain the possible causality of the phenomenon on the Covid-19 pandemic. If this is confirmed, these studies will provide much needed new tools to be able to predict the future behavior of the pandemic in other areas of the world.

Two points for a short discussion: 1) The Covid-19 low mortality fringe includes Norway, a country that, compared with its neighbor Sweden, is notorious for having had a much milder version of the pandemic, according to conventional wisdom, thanks to a stricter social distancing policy. Whether the model in the present paper can provide an additional explanation, is up for discussion. 2) As can be appreciated in the maps, regions like Eastern Andalucia in Spain or Provence in France can be considered areas of influence of the Gulf Stream/Atlantic Ocean through the Strait and the NorthPyrenean corridors, respectively, or alternatively, they could be deemed as zones of interaction with Western Mediterranean currents/winds.

From the very beginning of the pandemic, different models have attempted to find a link between weather variables and the Covid-19 pandemic. To date, none of these models have been able to generate accurate predictive tools to forecast future spread routes, let alone, disease outcomes ${ }^{[3][4][5][6]}$.

To the best of my knowledge, this is the first time that a link between a major Ocean Current and the outcome of the Covid19 pandemic has been laid out. I showed here that there are sharp regional differences in disease outcome within the same country, which implies that the explanation could be found in factors other than restriction policies during the pandemic or in social practices. Indeed, the data presented here suggests that the Gulf Stream or other weather factors (i.e. wind currents) of similar geographic distribution ${ }^{[2]}$ could account for the striking contrast in disease outcomes between intranational regions.

Besides the need for further deep analysis of the data, this observation also warrants future studies on the influence of other major Ocean Streams in the spread and mortality of the disease. A point in case: Are the big differences in the impact of the pandemic on two major US cities, LA and SF, explicable in part by the influence of another ocean current, the North Pacific Stream, or of other meteorological factors? I believe that this and other similar ones are questions worth pondering. Whether they could shed some new light into the complex intricacies of the SARS-CoV2 virus, only future research efforts 
will tell.

\section{References}

1. ' Carlos Rodriguez. (2020). Good news from Alsace: the Covid-19 pandemic is (almost) over. NOW WHAT?. Qeios. doi:10.32388/UO6RT1.

2. ${ }^{\text {a, b }}$ R. Seager, D. S. Battisti, J. Yin, N. Gordon, N. Naik, A. C. Clement. (2002). Is the Gulf Stream responsible for Europe's mild winters? Q. J. R. Meteorol. Soc., vol. 128 (586), 2563-2586. doi:10.1256/qj.01.128.

3. ' Sonal Gupta, Gourav Singh Raghuwanshi, Arnab Chanda. (2020). Effect of weather on COVID-19 spread in the US: A prediction model for India in 2020. Science of The Total Environment, vol. 728, 138860. doi:10.1016/.scitotenv.2020.138860.

4. ^ Jingui Xie, Yongjian Zhu. (2020). Association between ambient temperature and COVID-19 infection in 122 cities from China. Science of The Total Environment, vol. 724 , 138201. doi:10.1016/j.scitotenv.2020.138201.

5. ^ Te Faye Yap, Zhen Liu, Rachel A. Shveda, Daniel Preston. (2020). A Predictive Model of the Temperature-Dependent Inactivation of Coronaviruses. doi:10.26434/chemrxiv.12152970.v1.

6. ^Raghav Awasthi, Aditya Nagori, Pradeep Singh, Ridam Pal, Vineet Joshi, Tavpritesh Sethi. (2020). Temperature and Humidity Do Not Influence Global COVID-19 Incidence as Inferred from Causal Models. doi:10.1101/2020.06.29.20142307. 